\title{
Recent Insights on Genetic Testing in Primary Prostate Cancer
}

\author{
Mona Kafka ${ }^{1}\left(\mathbb{D} \cdot\right.$ Cristian Surcel $^{2,3} \cdot$ Isabel Heidegger $^{1}$
}

Accepted: 17 April 2021 / Published online: 12 June 2021

(c) The Author(s) 2021

\begin{abstract}
Prostate cancer ( $\mathrm{PCa})$ is one of the most common cancers in developed countries. The results of large trials indicate that the proportion of $\mathrm{PCa}$ attributable to hereditary factors is as high as $15 \%$, highlighting the importance of genetic testing. Despite improved understanding of the prevalence of pathogenic variants among men with $\mathrm{PCa}$, it remains unclear which men will most benefit from genetic testing. In this review, we summarize recent evidence on genetic testing in primary PCa and its impact on routine clinical practice. We outline current guideline recommendations on genetic testing, most importantly, for mutations in BRCA1/2, MMR, CHEK2, PALB2, and HOXB13 genes, as well as various single nucleotide polymorphisms associated with an increased risk of developing PCa. The implementation of genetic testing in clinical practice, especially in young patients with aggressive tumors or those with positive family history, represents a new challenge for the coming years and will identify men with pathogenic variants who may benefit from early screening/intervention and specific therapeutic options.
\end{abstract}

\section{Key Points}

Genetic testing is an important part of personalized diagnosis and treatment of prostate cancer $(\mathrm{PCa})$.

Recent clinical studies have highlighted specific genes (e.g., BRCA 1/2, PALB2, CHEK, HOXB13) and single nucleotide polymorphisms as special genes of interest.

One future goal of genetic testing is to detect men harboring an increased risk of lethal PCa.

Isabel Heidegger

isabel-maria.heidegger@i-med.ac.at

1 Department of Urology, Medical University Innsbruck, Anichstreet 35, 6020 Innsbruck, Austria

2 Carol Davila University of Medicine and Pharmacy, Bucharest, Romania

3 Department of Urology, Fundeni Clinical Institute, Bucharest, Romania

\section{Introduction}

Prostate cancer (PCa) is one of the most common malignancies in developed countries [1]. Since the introduction of prostate-specific antigen (PSA) measurement in screening programs, the number of patients with metastatic disease has substantially reduced as diagnosis is often achieved at an early and thus curable stage of disease. However, highly aggressive variants of the disease are also associated with significant morbidity and mortality rates [2]. Therefore, the identification of aggressive and fatal forms of PCa that need urgent treatment is still a major challenge in clinical practice.

Family history (FH) is a primary risk factor for being diagnosed with PCa. Epidemiologic studies have shown that men with a first-degree relative (father and/or brother) with PCa are at increased risk of developing the disease [3]. According to the results of large trials, the proportion of PCa attributable to hereditary factors has been estimated at 5-15\% [4-6]. A recently published cross-sectional study of 3607 unselected men with PCa [7] found pathogenic germline variants in $17.2 \%$ of the patients. Interestingly, $37 \%$ of these patients would not have met the current criteria for genetic testing, according to their FH and risk factors [7]. Furthermore, twin studies have confirmed a strong genetic association with a higher concordance rate (27 vs. $7 \%$ ) observed for monozygotic twins than for dizygotic twins $[8,9]$. The twin study by Lichtenstein et al. [8] reported that 
almost $42 \%$ of all PCa cases were attributed to inherited factors.

However, the impact of positive $\mathrm{FH}$ is variable and depends on several factors such as age, degree of relative, and extensive cancer pedigree. Carter et al. [10] reported that the cumulative proportion of PCa cases attributable to high-risk susceptibility alleles was $43 \%$ for men aged $<55$ years but accounts for only $9 \%$ for men aged $>85$ years. A recent meta-analysis also confirmed that men with an affected brother are at higher relative risk than men with an affected father (relative risk 3.4 vs. 2.2, respectively) [11]. Thus, it has been demonstrated that proper quantification of the FH should include the number of affected relatives, age at diagnosis, and status of close relatives, which in combination allow better estimation of the individual risk of being diagnosed with $\mathrm{PCa}$ [12].

A FH of breast cancer (BCa) and/or ovarian cancer (OCa) has also been identified as a risk factor associated with $\mathrm{PCa}$ development [13]. A well-designed study demonstrated that the estimated relative risk of being diagnosed with $\mathrm{PCa}$ was 2 for men with a first-degree relative (mother/sister) with $\mathrm{BCa}$ and 1.7 for those with a first-degree relative with $\mathrm{OCa}$ [14]. This risk may be associated with germline mutations in $\mathrm{BCa}$ genes 1 and $2(B R C A 1 / 2)$, which represent the most frequent event reported in the literature [13]. Generally, germline mutations are defined as any detectable gene variation occurring in germ cells associated with an increased risk of developing various cancers. These alterations are inheritable and can be passed on to offspring. Conversely, somatic mutations are alterations that can occur in the DNA sequence of each somatic cell from any organism. These gene alterations are commonly acquired and cannot be passed on to offspring. A broad integration of genetic testing of both germline and somatic variants is meaningful and reflects the molecular variability of the tumors and different clinical behaviors. In addition, the role of environmental factors has also been suggested to overestimate the hereditary impact. Admittedly, the risk associated with FH remains independently significant even after adjustment for environmental factors, reinforcing the role of genetic predisposition [15].

Nevertheless, some data remain inconclusive regarding the impact of this genomic and molecular heterogeneity on clinical outcomes and cancer management $[16,17]$. However, emerging evidence in genetics, the development of new techniques, and the uptake of specific target therapies such as poly (ADP-ribose) polymerase (PARP) inhibitors, has encouraged enhanced research in this area. A recent landmark review highlighted strong evidence that specific germline mutations are associated with an increased risk for high-grade PCa tumors and impact the clinical course [18]. Hart et al. [19] reported $17.4 \%$ germline mutations among patients with progressed metastatic castration-resistant $\mathrm{PCa}$; to a large extent, these were identified in BRCA2.
Furthermore, Loeb et al. [20] provided relevant data for precise recommendations for genetic testing for different professional societies as a key component of PCa management. As described in the review, genetic testing is broadly recommended in metastatic PCa with a focus on BRCA2; however, the recommendations for primary PCa vary between societies [20]. Szymaniak et al. [21] highlighted the challenges faced by practitioners with evidence increasingly supporting genetic workups for patients with PCa combined with a lack of experience in genetic testing in clinical practice.

Nevertheless, we are convinced that personalized medicine based on the evaluation of individualized risk profiles is the key for the future. With this review, we aim to elucidate current evidence on genetic testing in the primary diagnosis of $\mathrm{PCa}$ according to our predefined inclusion criteria. We also provide information on specific germline mutations associated with an increased risk of being diagnosed with $\mathrm{PCa}$, accurate panels for multiple-gene testing, and pathogen single nucleotide polymorphisms (SNPs). We also provide insight into genetic testing in regard to liquid biopsies and summarize the recommendations of different guidelines.

\section{Methods}

\subsection{Search Strategies and Sources}

A literature review of PubMed was performed in September 2020. Searches were restricted to studies published in English within the last 10 years. Keywords were used to predefine a MeSH (medical subject heading) term for the literature search, including hereditary AND prostate AND cancer AND genetic AND testing. Results were subsequently extracted and imported into an Excel sheet (Table 1 in the electronic supplementary material).

\subsection{Data Extraction and Eligibility Criteria}

In total, 111 titles were retrieved in the primary database search, and the results were imported into an Excel spreadsheet (2013 version). Manual screening was performed to exclude duplicates. Articles were identified by reading the abstracts and, if there was still uncertainty, a full-text analysis was performed. We included only clinical studies that focused on genetic testing in the primary diagnosis of PCa. We excluded manuscripts with data based on animal or in vitro studies, that investigated other cancer entities, that did not include any genetic testing, or that did not report an impact on medical practice (e.g., insights on economic aspects or technical background of genetic testing). Review articles were also eliminated. After studies not meeting our inclusion criteria (see Sect. 2.3) were eliminated, all studies on genetic testing in the primary 
Table 1 Register of studies discussed in the manuscript

\begin{tabular}{|c|c|c|}
\hline Study & Focus & Comment \\
\hline Kerr et al. [29] & $\mathrm{LS}, B R C A 1 / 2$ & $\mathrm{LS} \uparrow \mathrm{PCa}$ risk \\
\hline Huynh-Le et al. [45] & SNPs & Age-specific risk for PCa calculated with the PHS \\
\hline Cybulski et al. [39] & $\begin{array}{l}\text { BRCA1, CHEK2, NBS1, } \\
\text { HOXB13, SNPS }\end{array}$ & CHEK2 is associated with $\uparrow$ detection of PCa and $\uparrow$ number of SNPs \\
\hline Patel et al. [34] & BRCA1/2 & $B R C A 2 \uparrow$ risk of $\mathrm{PCa}$ with a $\mathrm{GS} \geq 8$ \\
\hline Yang et al. [55] & $P A L B 2$ & No correlation found with $\mathrm{PCa}$ \\
\hline Mersch et al. [35] & $B R C A 1 / 2$ & $B R C A 2$ is associated with $\uparrow$ age-specific risk for $\mathrm{PCa}$ \\
\hline Silvestri et al. [36] & $B R C A 1 / 2$ & $B R C A 2$ is associated with $\uparrow$ risk for $\mathrm{PCa}$ and aggressive forms \\
\hline Pakkanen et al. [25] & Hereditary vs. SPCa & Earlier disease onset and higher PSA in patients with FH \\
\hline Heise et al. [58] & PON1 & No correlation found with $\mathrm{PCa}$ \\
\hline Rosenthal et al. [50] & MGPT & $\begin{array}{l}\uparrow \text { number of genetic mutations in pan-cancer gene panels than in single-syndrome gene } \\
\text { panel testing }\end{array}$ \\
\hline Pritzlaff et al. [48] & MGPT & $\begin{array}{l}\text { BRCA1/2, ATM, BRIP1, CHEK2, NBN, BRAD1, MSH2, MSH6, MLH1, PMS2, EpCAM } \\
\text { mutations in } 9.4 \% \text { of patients with hereditary PCa }\end{array}$ \\
\hline Sutcliffe et al. [37] & CHECK2 & Among $C H E K 2$ mutation carriers, PCa was the second-most common tumor with $20 \%$ \\
\hline Ābele et al. [59] & NBS1 & No correlation found with $\mathrm{PCa}$ \\
\hline Kwon et al. [52] & MGPT & $13.8 \%$ of patients with PCa had PVs, mostly in $B R C A 2$ \\
\hline Mantere et al. [56] & FANCA/FANCG/FANCI & No correlation with $\mathrm{PCa}$ \\
\hline Heise et al. [41] & HOXB13 & HOXB13 mutations $\uparrow$ risk for PCa and a $\downarrow$ OS \\
\hline Wallander et al. [47] & SNPs & \\
\hline Pilié et al. [49] & MGPT & $10.8 \%$ pathogenic and likely pathogenic mutation among patients with cancer \\
\hline Ewing et al. [40] & HOXB13 & HOXB13 mutations $\uparrow$ risk for $\mathrm{PCa}$, especially for early-onset disease \\
\hline Momozawa et al. [51] & MGPT & $2.8 \%$ of patients with PCa had PVs, associated with early disease onset \\
\hline Slavin et al. [54] & cfDNA & $3.4 \%$ mutation of cfDNA in $\mathrm{PCa}$ \\
\hline Page et al. [32] & $B R C A 1 / 2$ & $\begin{array}{l}\uparrow \text { incidence of PCa among } B R C A 2 \text { carriers with } \uparrow \text { rate of early-onset disease and } \uparrow \text { rate of } \\
\text { clinically significant cancers }\end{array}$ \\
\hline Cremers et al. [46] & SNPs & No tool to differ between sporadic and hereditary PCa \\
\hline Southey et al. [38] & CHECK2, PALB2, ATM & $C H E K 2$ was associated with $\uparrow$ risk for $\mathrm{PCa}$ \\
\hline Seibert et al. [44] & SNPs & PHS to calculate age of onset of PCa \\
\hline MacInnis et al. [42] & HOXB13 & HOXB13 carriers have a 16.4 -fold $\uparrow$ age-specific-risk \\
\hline Chandrasekar et al. [27] & Hereditary vs. SPCa & $19.5 \%$ germline mutation among suspected hereditary PCa connected to an HCS \\
\hline Kote-Jarai et al. [43] & HOXB13 & 2.9-fold $\uparrow$ risk for $\mathrm{PCa}$ \\
\hline Haraldsdottir et al. [30] & LS & Patients with LS have fivefold $\uparrow$ risk for PCa \\
\hline Beebe-Dimmer et al. [26] & Hereditary vs. SPCa & $\begin{array}{l}\text { FH of familial PCa } \uparrow 2.3 \text {-fold the risk for PCa, fourfold } \uparrow \text { risk for early-onset disease } \\
\text { among hereditary PCa }\end{array}$ \\
\hline Bancroft et al. [31] & BRCA1/2 & $\uparrow$ detection of PCa among $B R C A$ mutation carriers \\
\hline Maia et al. [33] & $B R C A 1 / 2, \mathrm{LS}$ & $\begin{array}{l}\text { MMR and } B R C A 1 / 2 \text { mutations were associated with early-onset and aggressive subtypes } \\
\text { of PCa }\end{array}$ \\
\hline Barrow et al. [24] & LS & Tenfold $\uparrow$ risk for PCa among $M S H 2$ mutation carriers \\
\hline Cardoso et al. [33 OR 61] & $P P M 1 D$ & No clear correlation \\
\hline
\end{tabular}

cfDNA cell-free DNA, FH family history, GS Gleason Score, $H C S$ hereditary cancer syndrome, $L S$ Lynch syndrome, $M G P T$ multigene panel testing, $M M R$ mismatch-repair deficiency, $O S$ overall survival, $P C a$ prostate cancer, $P H S$ polygenetic hazard score, $P S A$ prostate-specific antigen, $P V s$ pathologic variants, $S N P$ single nucleotide polymorphism, $S P C a$ sporadic $\mathrm{PCa}$

diagnosis of PCa were integrated into our analysis. MK performed the selection and extraction process. Studies related to genetic testing in advanced and metastatic $\mathrm{PCa}$ were beyond the scope of this manuscript.

\subsection{Evidence Synthesis}

Of 109 initial studies, 15 were excluded from final analysis as they covered mainly the economic or psychological landscape of genetic testing. A further 19 publications presented 
the results of genetic testing associated with other cancer entities such as BCa. Four publications did not contain information on genetics. A further 16 reviews on genetic testing and two published consensus decisions were also excluded. After evaluation of all primary search results, 34 studies were included in the detailed analysis for this review. Figure 1 depicts the data selection process in a PRISMA (Preferred Reporting Items for Systematic Reviews and MetaAnalyses) flowchart.

\section{Results}

Our review provides an overview of the PCa genomic landscape with an emphasis on cardinal mutations and alterations consistently observed in the literature. Evidence from all 34 included clinical trials was grouped and summarized in suitable categories (Table 1). First, we present studies focusing on hereditary $\mathrm{PCa}$ compared with sporadic $\mathrm{PCa}$ (SPC). Next, we discuss studies of hereditary non-polyposis colorectal cancer (HNPCC) and Lynch syndrome (LS) and describe specific gene mutations and their impact on $\mathrm{PCa}$, followed by a section on SNPs. We also report some studies focusing on multigene panel testing (MGPT) and cell-free DNA (cfDNA).

\subsection{Hereditary Versus Sporadic Prostate Cancer}

In recent years, advances in sequencing technologies, particularly high-throughput platforms, have permitted the discovery of novel genes responsible for cancer inheritance, facilitating efficient genetic screening. Generally, a hereditary cancer syndrome (HCS) is a genetic predisposition to certain types of cancer, often associated with an early disease onset, caused by inherited pathogenic variants (PVs) in one or more genes. Most HCSs exhibit autosomal dominant inheritance, for example, LS, Li-Fraumeni syndrome, or Cowden syndrome [22-24]. Hereditary PCa is defined based on FH and includes patients with three or more affected relatives or at least two relatives who have developed early-onset PCa (aged $<55$ years) $[16,17]$. In this section, we report on three trials in hereditary PCa.

Generally, the onset of hereditary PCa is 6-7 years earlier than that of SPC [16, 17]. Pakkanen et al. [25] compared the incidence and aggressiveness of $\mathrm{PCa}$ in a Finnish population of 202 families with 617 patients with familial $\mathrm{PCa}$ and a control
Fig. 1 Flow chart of literature search
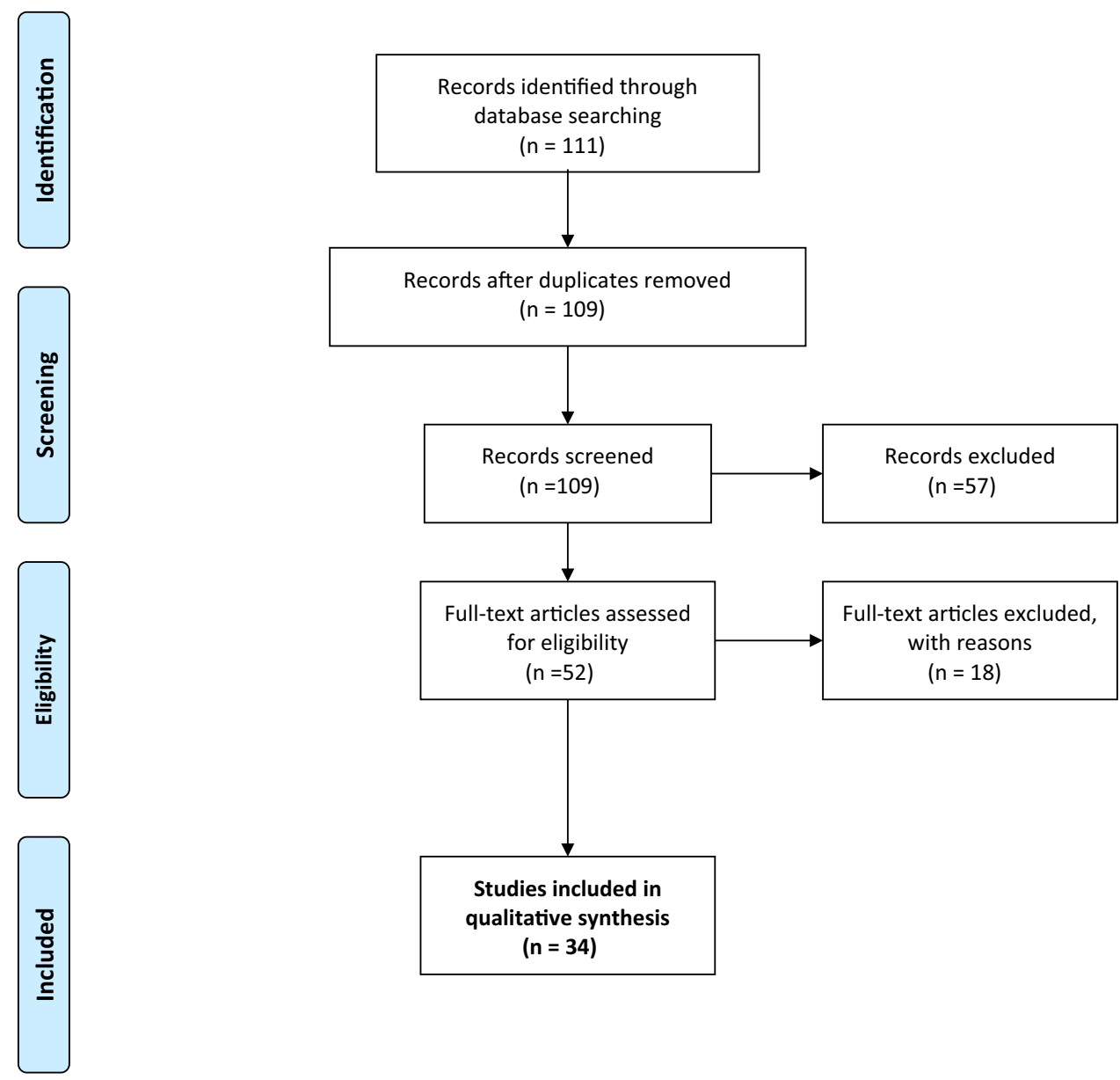
group of 3011 patients with PCa without FH of PCa. Only men with two or more affected first-degree relatives were included in the familial PCa group. The results showed an earlier onset of PCa (mean age at diagnosis 66 years) and a higher initial PSA level (mean $12 \mathrm{ng} / \mathrm{ml}$ ) in patients with familial PCa than in those with SPC (mean 68 years, PSA $9.5 \mathrm{ng} / \mathrm{ml}$ ) [25].

However, there was no difference in T- or M-stage among patients who underwent prostatectomy. Interestingly, the familial PCa group had lower Gleason scores (GS), with a GS $\geq 8$ seen in only $12 \%$ of the patients with familial PCa after prostatectomy, compared with $17 \%$ in the control group. Follow-up data showed that significantly more males with FH died from PCa (61 vs. 31\%). A difference in cancerspecific survival (CSS) could not be demonstrated [25].

Beebe-Dimmer et al. [26] evaluated the risk of $\mathrm{PCa}$ in males with both familial PCa and HCS using a large database to identify patients with a known $\mathrm{FH}$ of either $\mathrm{PCa}$, $\mathrm{BCa}$, or OCa [26]. Of 619,630 included males, $5.9 \%$ were diagnosed with PCa. Among them, 7\% of all PCa met the criteria for early-onset disease, $11 \%$ had lethal disease, and $41 \%$ were categorized as having clinically significant cancers. A positive FH of PCa was defined as two or more firstor second-degree relatives with PCa on the same bloodline, whereas hereditary $\mathrm{PCa}$ was characterized according to the following criteria: three or more first-degree relatives with $\mathrm{PCa}$, three or more relatives spanning three generations out to third-degree relatives and all on the same ancestral line and at least two first- or second-degree relatives diagnosed with PCa before the age of 55 years. Patients with a background of familial PCa had a 2.3-fold increased risk of PCa, whereas patients with a FH of $\mathrm{BCa}, \mathrm{OCa}$, or $\mathrm{LS}$ had a modestly increased risk. Of note, hereditary PCa was associated with a nearly fourfold increased risk of early-onset PCa, clinically significant disease, and lethal features [26].

Recently, Chandrasekar et al. [27] prospectively assessed the prevalence of HCS and germline mutations among a cohort of probands reporting a $\mathrm{FH}$ of $\mathrm{PCa}$ [27]. Of 345 participants, $63.8 \%$ met the inclusion criteria for at least one HCS with a potential association with hereditary PCa. Interestingly, hereditary $\mathrm{BCa}$ or OCa was identified in a higher percentage of the African American patients than the Caucasian patients ( 90.2 vs. $74.6 \%$ ). Furthermore, germline mutations were found in $19.5 \%$ of all patients with suspected hereditary PCa linked to an HCS [27].

In summary, a significant increased risk of being diagnosed with early-onset $\mathrm{PCa}$ was observed in patients with a FH of PCa.

\subsection{Hereditary Non-polyposis Colorectal Cancer/ Lynch Mutations}

HNPCC, also called LS, is a syndrome based on a mutation in DNA mismatch-repair (MMR) genes and is a predisposing factor for the development of several cancer entities, predominantly colorectal cancer (CRC). Generally, all genes associated with MMR mechanisms can display mutations in LS, but the most common alterations involve $\mathrm{MSH}$, $M S H 6$, $M L H 1, P M S 2$, and EpCAM. Investigation of the occurrence of PCa in families enriched for LS suggested an increased risk of sentinel coexistence in the current literature [28]. We identified three relevant studies on this topic, which we now discuss in detail.

Kerr et al. [29] performed a subcohort analysis of the IMPACT trial that included mainly patients with a FH of LS. One of four such patients was diagnosed with a GS 6 $\mathrm{PCa}$ and underwent radical prostatectomy. Genetic testing confirmed a family mutation of the MSH6 gene [29].

Similarly, another working group analyzed the risk of developing PCa in 11 patients with LS [30]. Within the cohort, two patients were carriers of $M S H 2$ mutations, two of MSH6, one of MLH1, and one of PMS2. Overall, this trial showed that patients with LS had an almost fivefold increased risk of developing PCa compared with the general population. Of these patients with $\mathrm{PCa}, 72 \%$ were diagnosed with localized tumor, $14 \%$ with locally advanced cancer, and $14 \%$ with metastatic disease. One limitation of this article was that the disease status of four cases could not be determined, and a classification according to GS was not included in the report. In accordance with their conclusions, no correlation with early-onset PCa or aggressiveness was observed [30].

Another study aimed to identify the prevalence of various urological cancers among patients with LS [24]. In total, 821 male Lynch mutation carriers and their untested male firstdegree relatives were identified from a Manchester regional LS database. The primary endpoint was time to development of urological malignancy. Eight patients with PCa were identified, among them one patient aged $<60$ years at diagnosis. Statistical analysis performed in this trial reported in an almost tenfold increased risk of developing PCa in $\mathrm{MSH} 2$ carriers. No such association was found for bladder cancer, and a correlation between $M S H 2$ and $M L H 1$ mutations and upper tract urothelial carcinomas was confirmed [24].

In summary, the combination of evidence from molecular and risk studies in the current literature supports an association between PCa and LS, so PCa screening should be recommended in mutation carriers. Note that two of four reported studies assessed a small cohort of patients, so the resulting data should be evaluated with caution.

\subsection{Specific Predisposition Genes}

\subsubsection{BRCA1/2}

$B R C A 1 / 2$ genes are important for genomic stability and are predominantly involved in the process of double-strand 
DNA damage repair mechanisms during the cell cycle [13]. Mutations in BRCA1/2 genes are mostly known for their increased risk for the development of $\mathrm{BCa}$ [13]. However, inherited mutations in $B R C A$ genes are associated with an increased risk of developing $\mathrm{OCa}, \mathrm{PCa}$, and other cancers. We report the results of eight clinical trials focusing on associations between BRCA1/2 mutations and the incidence of PCa.

A large international multicenter screening study (IMPACT) addressed this issue by comparing patients with BRCA1/2 germline mutations and non-mutation carriers [31, 32]. Men with a PSA level $>3 \mathrm{ng} / \mathrm{ml}$ aged $40-69$ years underwent PSA testing and transrectal ultrasound-guided biopsy, and those with a PSA level $<3 \mathrm{ng} / \mathrm{ml}$ underwent further annual PSA measurements. The first results were published in 2014, after 1 year of screening, and already revealed an increased detection rate of $\mathrm{PCa}$ among $B R C A$ mutation carriers [31]. Subsequently, a subset analysis of 47 men with an $\mathrm{FH}$ of $B R C A 1 / 2$ mutations was published and showed that one in seven (14\%) BRCAl and one in $20(5 \%)$ $B R C A 2$ mutation carriers were diagnosed with PCa [29]. Interestingly, no single case of PCa was found among the non-carrier patients who underwent biopsy (no BRCA1/2) [29]. Recently, the interim data of the large IMPACT study in 3027 patients with verified $B R C A 1 / 2$ mutations and nonmutation carriers (919 BRCAl carriers, 709 BRCAl noncarriers, 902 BRCA2 carriers, $497 B R C A 2$ non-carriers) who underwent PSA screening over 3 years was published [32]. A total of 357 biopsies were performed, with subsequent diagnosis of $112 \mathrm{PCa}$ cases. According to study results, higher biopsy compliance was seen in $B R C A 2$ carriers than in BRCA2-negative patients ( $73 \%$ vs. $60 \%$ ). Furthermore, a higher incidence rate per 1000 males/year was seen for $B R C A 2$ carriers, with a noticeable earlier onset of disease (61 vs. 64 years; $p=0.04$ ) as well as a higher percentage of clinically significant cancers compared with $B R C A 2$ non-carriers ( $77 \%$ vs. $40 \% ; p=0.01$ ) [32]. Interestingly, no different clinical characteristics were found in the group of BRCA1 mutation carriers [32].

Maia et al. [33] assessed the incidence of BRCA1/2 mutations or LS in 462 males with early-onset PCa or hereditary $\mathrm{PCa}$ [33]. All patients were tested for six germline mutations that are particularly common in Portugal, and 38 of them were selected for complete sequencing of $B R C A 1 / 2$ and/or $M L H 1, M S H 2$, and MSH6. Two patients harbored the same $M S H 2$ mutation, and a third patient carried a Portuguese $B R C A 2$ founder mutation. None of the alterations were identified in the 288 control subjects. Furthermore, they reviewed $62 \mathrm{PCa}$ diagnoses in all hereditary $\mathrm{BCa} / \mathrm{OCa}$ $(n=161)$ and LS $(n=124)$ families previously diagnosed and found five more $B R C A 2$ mutation carriers and two additional $\mathrm{MSH} 2$ mutation carriers. Interestingly, the clinicopathological characteristics of mutation carriers were in line with earlier data suggesting an aggressive PCa phenotype [33].

A recent landmark study elucidated the association between BRCA1/2 mutations and high-risk PCa [34]. A large multicenter database had 6500 male BRCA1/2 mutation carriers eligible for analysis. The primary endpoint was to evaluate whether gene mutations were associated with risk of overall PCa and high-grade tumors. Results demonstrated that specific BRCA2 mutations may be associated with an elevated risk of developing aggressive PCa. Specific pathogenic sequence variants in the genome, named "prostate cancer cluster regions" were identified on $B R C A 2$ genes. In contrast, mutations in $B R C A l$ were not associated with a higher risk of developing PCa. The study results suggested specific PVs in BRCA2 that might be useful as an additional factor in screening for clinically significant PCa [34]. Similarly, Mersch et al. [35] evaluated a cohort of 1072 mutation carriers and revealed an increased age-specific risk of developing $\mathrm{PCa}$ in males with $B R C A 2$ mutations compared with the general population.

A large international retrospective multicenter study included data from 6902 males carrying BRCA1/2 mutations [36]. In total, 1376 patients had at least one malignancy. Again, harboring a $B R C A 2$ mutation was associated with a higher risk of being affected by any cancer, with the highest frequency reported for $\mathrm{BCa}$ and $\mathrm{PCa}$. The mean age for the diagnosis of PCa was 63.2 years. This study also confirmed that there were significantly more $B R C A 2$ mutation carriers than BRCAl mutation carriers in the PCa group. Similarly, more aggressive cancers were reported in $B R C A 2$ variants [36]. An additional finding reported by Chandrasekar et al. [27] was that germline mutations were most frequently found in BRCA genes in African American men, whereas they were found in a broad spectrum of predisposition genes in Caucasian men, suggesting a higher frequency of $B R C A$ mutations in the African American population [27].

In summary, the impact of BRCAl/2 mutations on $\mathrm{PCa}$ development has been broadly demonstrated, with studies showing that faults in the $B R C A 2$ gene have an increased risk of being associated with $\mathrm{PCa}$ and mainly in aggressive forms.

\subsubsection{CHEK2}

Checkpoint kinase 2 (CHEK2) is a tumor-suppressor gene involved in the process of DNA repair, apoptosis, and cellcycle arrest. Its mutation confers an increased risk for $\mathrm{BCa}$, but its involvement in $\mathrm{PCa}$ has not been confirmed. With the aim of clarifying the association between $C H E K 2$ mutation and PCa risk, we present the results of three studies on this topic.

Sutcliffe et al. [37] analyzed different phenotypes of CHEK2 mutation associated with the occurrence of various 
malignancies. PVs in $C H E K 2$ mutation were analyzed in 2508 patients (93\% females; $83 \%$ Caucasians). Along with mainly heterozygous $C H E K 2$ mutations, 21 patients expressed biallelic CHEK2 PVs. Among the heterozygous CHEK2 study group, the most frequently reported malignancies were female $\mathrm{BCa}(59.9 \%), \mathrm{PCa}(20.1 \%)$, and male $\mathrm{BCa}$ $(11.8 \%)$. In the homozygous group, female (72\%) and male (66\%) BCa and CRC (12\%) were most commonly recorded [37].

Southey et al. [38] aimed to evaluate the risk of PCa in patients with rare variants of CHECK2, PALB2, and ATM. Ten different genotypes were analyzed in 22,301 patients with PCa and 22,320 controls. Their results revealed evidence for an elevated PCa risk in African males with a $C H E K 2$ c. $1343 \mathrm{~T}>\mathrm{G}$ variant and for European males with a CHEK2 c. $1312 \mathrm{G}>\mathrm{T}$ variant [38].

A large clinical trial published by Cybulski et al. [39] included 2907 patients and evaluated the impact of genotyping (18 different alleles) on the detection of PCa in primary screening. PSA levels and digital rectal examination (DRE) status were determined at study inclusion. A prostate biopsy was performed in 323 patients with PSA $\geq 4 \mathrm{ng} / \mathrm{ml}$ or a positive DRE status. All patients were genotyped for various alleles in BRCA1, CHEK2, NBS1, and HOXB13 and for nine low-risk SNPs. Study results showed that PCa was diagnosed on the basis of PSA and DRE status in only $4.6 \%$ of enrolled patients. Instead, genotyping results revealed that only patients with a mutation in one CHEK2 allele (I157T) combined with elevated PSA/abnormal DRE had a higher PCa detection rate (10.2\%). Moreover, the probability of $\mathrm{PCa}$ being detected increased with the number of variant SNP genotypes observed, from $1.2 \%$ for carriers of no risk genotype to $8.6 \%$ for carriers of six or more risk genotypes [39].

In summary, an increased risk for the development of $\mathrm{PCa}$ was observed in $C H E K 2$ mutation carriers.

\subsubsection{HOXB13}

Homebox protein 13 (HOXB13) is involved in the embryological process of organ differentiation and regulates the activity of other genes. Given our understanding of its influence on the transcription of androgen receptor target genes, a correlation with PCa was suggested. We present the evidence provided by four clinical trials investigating $H O X B 13$.

Ewing et al. [40] conducted one of the first studies to address the potential increased risk for $\mathrm{PCa}$ in patients with germline mutation in $\mathrm{HOXB13}$. The study population included subjects with PCa who had at least one living first- or second-degree relative with $\mathrm{PCa}$, or those diagnosed before the age of 55 years, or families with hereditary disease; each had at least three first-degree relatives with PCa. Healthy males undergoing screening for PCa were selected as the control group. The genotype data of 5083 patients with PCa and 1401 healthy controls were analyzed. In total, $1.4 \%$ of patients in the PCa group and $0.1 \%$ of those in the control group were identified as G84E HOXB13 carriers (odds ratio 20) [40]. However, a subgroup analysis adjusted for age of diagnosis and $\mathrm{FH}$ showed that G84E mutation carriers had significantly earlier disease onset and a positive $\mathrm{FH}$ of PCa [40]. Furthermore, the group with early-onset disease and a positive $\mathrm{FH}$ had the highest mutation carrier rate [40].

Similarly, Heise et al. [41] recently investigated the incidence of G84E germline mutation of $H O X B 13$ in patients with PCa. A mutation in $H O X B 13$ was found in $2.3 \%$ of all patients with $\mathrm{PCa}$ but in none of the healthy controls. The authors reported that $66 \%$ of mutation carriers had a positive FH that met the criteria for the definition of hereditary PCa. Furthermore, their 5-year follow-up data indicated that overall survival (OS) was shorter in $\mathrm{HOXB} 13$ mutation carriers than in negative patients, although mutation carriers were older at disease onset [41]. No correlation with PSA level or clinical stage of disease at diagnosis was reported [41].

Another population study on G84E mutation of $\mathrm{HOXB13}$ in 1384 participants with early-onset $(<60$ years) $\mathrm{PCa}$ in Australia observed a G84E mutation in $1.4 \%$ of the study participants. Of the group with G84E mutations, six males (32\%) had an FH of PCa. Therefore, the age-specific incidence for carriers was estimated to be 16.4 times that for the general Australian population [42].

A similar study performed genotyping for a G84E mutation in 8652 patients with $\mathrm{PCa}$ and 5252 healthy controls [43]. A G84E mutation was found in $1.5 \%$ of patients with PCa compared with $0.5 \%$ of the healthy males, indicating a 2.9-fold increased risk. This study also reported an enhanced risk for patients with an $\mathrm{FH}$ or early-onset $\mathrm{PCa}$. No correlation with clinical stage, GS, or PSA level was observed. Moreover, no impact on OS or CSS rates was observed, so no prognostic value could be verified [43].

In conclusion, a highly increased risk for PCa among HOXB13 mutation carriers (up to 20 -fold) was found.

\subsection{Single Nucleotide Polymorphism Genotyping}

An SNP is defined as a single base pair mutation at a specific locus [44]. Some SNPs have proven to be related to the development of various diseases and are currently used extensively to set up genetic screening programs for malignancies. We included four relevant studies investigating the impact of SNPs on PCa.

Seibert et al. [44] recently developed a polygenetic hazard score (PHS) that could predict the age of onset of aggressive PCa (defined as $\geq$ GS 7, T3-T4, PSA $\geq 10$ and/or nodal/ distant metastasis) based on the analysis of 54 SNPs and large patient databases [44]. This tool might therefore be useful in clinical practice when counseling patients on their 
risk and to identify the optimal age to start PCa screening in each patient [44]. Recently, this score was further improved by including age-specific PCa incidence data collected from large data registers [45]. The combination of this information with the PHS enabled the design of a personal risk calculator with better predictive accuracy in detecting clinically significant $\mathrm{PCa}$ at a specific age than the standard risk evaluation [45].

Given that SNPs do not only occur in patients with hereditary disease, Cremers et al. [46] recently elucidated the potential role of specific SNPs in differentiation between SPC and hereditary PCa. In total, 74 SNPs were genotyped in a population-based series of 620 patients with SPC, 313 patients with hereditary $\mathrm{PCa}$, and 1819 healthy males [46]. The study reported 62 SNPs associated with SPC and 64 SNPs in patients with hereditary PCa. However, there was an overlap of 56 SNPs in both groups, suggesting a similarity in genetic ethology and only a small difference recorded, although groups clearly differed from the controls. Consequently, the authors considered SNPs to have no discriminative value for SPC and hereditary PCa [46].

Wallander et al. [47] aimed to identify potential SNPs in patients with CRC, gastric cancer, or PCa. A total of 45 families with at least two members with CRC and at least one with PCa or gastric cancer were analyzed. Families with both LS and polyposis syndrome in their history were excluded. The linkage analysis identified five potential loci for concordant SNPs, but further assessment of the exome did not reveal any potential pathologic sequence [47].

In summary, the occurrence of specific SNPs is clearly more common in patients with $\mathrm{PCa}$ than in healthy males, and the risk of disease development seems to be proportionally related to an increasing number of SNPs.

\subsection{Multigene Panel Testing}

Because screening for one specific gene mutation is often insufficient, the implementation of specific gene panels for different tumor entities is gaining increasing interest. However, a clearly predefined screening panel able to identity patients with an increased risk of PCa is still lacking, so the need for development is high [48]. This section discusses five studies that used MGPT to assess the risk of developing PCa.

Pritzlaff et al. [48] recently published data on a gene panel (ProstateNext) including mutations in BRCA1/2, ATM, BRIP1, CHEK2, NBN, BRAD1, and MMR-deficiency genes (MSH2, MSH6, MLH1, PMS2, EpCAM). MGPT was performed in 1878 males diagnosed with PCa between 2012 and $2017 ; 9.4 \%$ were positive for the applied 14-gene panel ProstateNext. PVs were most frequently found in BRCA2 (3.8\%), ATM (2.7\%), and CHEK2 (2.5\%) but were also seen in all other tested genes except for RAD51D. Mutations in genes influencing therapeutic strategies in later stages of the disease (BRCA1/2, MMR genes) were found in $7.4 \%$ of all patients with $\mathrm{PCa}$ [48]. Since the occurrence of multiple cancers in patients might be another indicator of underlying genetic mutations, Pilié et al. [49] performed MGPT in patients with $\mathrm{PCa}$ and at least one other associated malignancy. The authors sequenced germline DNA from 102 patients with PCa using a MGPT and identified around 3500 variants. Nine protein-changing germline mutations were found across the following six genes: BRCA2, ATM, MLH1, BRIP1, PALB2, and FGFR3. Furthermore, likely pathogenic missense variants were found in $H O X B 13$ and $C H E K 2$. Considering that pathologic or likely pathologic germline mutations were found in $10.8 \%$ of all included males, a higher risk for underlying mutations in cancer-predisposing genes must be assumed in patients with $\mathrm{PCa}$ and at least one additional tumor entity [49].

A landmark study published by Rosenthal et al. [50] analyzed a panel of 25 genes tested in 252,233 individuals. The majority of the study population (92.8\%) met testing criteria for hereditary BCa and OCa and/or LS. Overall, 17,340 PVs were identified in 17,000 (6.7\%) tested individuals. The PVpositive rate was $9.8 \%$ among those with a personal cancer history compared with $4.7 \%$ in unaffected individuals. PVs were most common in BRCA1/2 (42.2\%) and other $\mathrm{BCa}$ genes $(32.9 \%)$ as well as the LS genes $(13.2 \%)$. Half the PVs identified among individuals who met only hereditary $\mathrm{BCa}$ and OCa-testing criteria were in genes other than BRCA1/2. Similarly, half of the PVs identified in individuals who met only LS-testing criteria were in non-LS genes. Furthermore, PVs associated with PCa were found in $15.5 \%$ of all tested individuals. These findings suggest that genetic testing with a pan-cancer panel provides relevant data with enhanced clinical utility over traditional single-gene or single-syndrome testing [50].

Another large study recently performed in Japan also analyzed PVs on the basis of an eight-gene panel in 7636 patients with $\mathrm{PCa}$ and 12,366 cancer-free control patients [51]. Of the patients with $\mathrm{PCa}, 2.8 \%$ were carriers of a PV compared with $0.8 \%$ of patients in the control group. A total of 136 PVs were found, but association with PCa risk was only statistically significant for variants located in $B R A C 2, H O X B 13$, and ATM. Another finding from this large study population was that patients who harbored PVs were younger at diagnosis and had a $\mathrm{FH}$ of $\mathrm{BCa}$ or pancreatic, lung, or liver cancer [51].

Another recently published study investigated the difference in germline mutations among patients with PCa with different ethnic backgrounds [52]. The study included 1351 men with PCa: 78\% Caucasian, 11\% Jewish, 3\% African American/Canadian, 2\% Hispanic, 2\% Asian/Pacific Islands, and 4\% "others". Overall, $13.8 \%$ of all males were carriers of a gene variant, the most frequent being BRCA2 (3.4\%), 
CHEK2 (2.8\%), MUTYH (1.8\%), and ATM (1.7\%). Of note, HOXB 13 was not included in this panel. Unlike the data published by Chandrasekar et al. [27], this study [52] did not reveal a correlation between specific genetic variants and different ethnicities. Interestingly, an increased number of patients $(6.7 \%)$ in the Jewish population had a BRCA2 variant compared with $2.8 \%$ of Caucasians [52].

In summary, MGPT represents the most promising tool available for gathering robust genetic information from patients in primary cancer screening.

\subsection{Germline Mutation Testing in Cell-Free Circulation Tumor DNA}

Given that genetic testing of tissue samples is often associated with tissue biopsies (if no archival tissue of the primary tumor or metastases is available), the development of non-invasive approaches is important. Liquid biopsies are increasingly gaining importance in modern oncology as a tool for germline testing using cfDNA from solid tumors, saliva, skin biopsies, or even the buccal mucosa [53]. For more information, refer to a recent review by Cheng et al. [53].

Slavin et al. [54] analyzed germline mutations in the cfDNA of patients with various advanced solid tumors, including PCa. cfDNA samples from 10,888 patients who underwent a liquid biopsy test (Guardant360; Guardant Health, Inc., Redwood City, CA, USA) were analyzed for prevalence of a putative germline mutation identified among 16 actionable hereditary cancer predisposition genes. The Guardant360 test detects single nucleotide variants, small and large indels (fusions of deletion and insert), copy number amplifications, and fusion events. cfDNA was extracted from the plasma, quantified, and then sequenced up to 15,000 times to average read depth. A germline mutation rate of $3.4 \%$ was found for $\mathrm{PCa}$, demonstrating that it is also possible to perform this test for cfDNA of various cancer subtypes such as $\mathrm{OCa}$ and $\mathrm{BCa}$ [54].

\subsection{Additional Tested Genes}

A few studies met our inclusion criteria but did not provide sufficient evidence for a clear correlation between a specific gene mutation and an increased risk of PCa. However, since several of these genes are still interesting and under further examination, we discuss seven of these studies.

$P A L B 2$ is a gene that encodes a protein involved in the binding and co-localization of $B R C A 2$ in nuclear foci. PVs in $P A L B 2$ are associated with a greater risk of developing $\mathrm{BCa}$ and are included in BCa screening panels. However, Yang et al. [55] conducted a multicenter study including 523 families and did not reveal any correlation with an increased risk for PCa. Given that mutations in downstream Fanconi anemia pathway genes, such as $B R C A 2$ and $P A L B 2$, are strongly correlated with an increased risk of $\mathrm{BCa}$, Mantere et al. [56] investigated the involvement of FANCA/FANCG/ FANCI gene mutations in the development of PCa in a Finnish population but found no significant association with cancer susceptibility from a clinical point of view.

Serum paraoxonase and arylesterase 1 (PONI), also known as A-esterase, is an enzyme encoded by the PONI gene, which is involved in the process of preventing damage caused by systemic oxidative stress [57]. Given increasing evidence of its involvement in the development of various cancers, Heise et al. [58] conducted a study focused on PCa but did not find any specific genotype correlated with an increased risk of $\mathrm{PCa}$. However, PON1 remains a gene of interest, and further trials are needed to elucidate a potential connection with $\mathrm{PCa}$.

Nibrin (NBS1) encodes an eponymous protein involved in the repair of double-strand breaks and is suggested to be a risk factor for the development of PCa. Ābele et al. [59] performed a prospective trial to evaluate the epidemiological features of hereditary PCa. An analysis for founder gene mutation in $N B S 1$ was performed in 280 patients with $\mathrm{PCa}$ and in 173 healthy controls. The authors found only one NBS1 mutation in both groups so could not show any predisposition for the development of PCa based on an NBS1 mutation [59].

The protein phosphatase 1D (PPM1D) gene encodes a homonymous enzyme involved in cellular stress response pathways. There is evidence that mutations in PPM1D are associated with $\mathrm{BCa}, \mathrm{OCa}, \mathrm{CRC}$, and non-small-cell lung cancer [60]. Cardoso et al. [61] studied patients with early-onset or hereditary PCa to investigate the prevalence of these mutations in the DNA extracted from white blood cells. Among 462 patients, two $(0.4 \%)$ truncating mutations in $P P M 1 D$ were found in two males, both subjects carrying the alterations. Additionally, non-synonymous germline mutations were found in nine subjects (1.95\%) with PCa but in none of the healthy controls. Further studies are needed to investigate this background and to analyze whether a mutation can be correlated with an increased risk of the development of PCa [61].

\section{Current Guideline Recommendations for Genetic Testing}

As genetic testing starts to play a vital role in the diagnosis of PCa, especially in young men with aggressive forms of the disease, different guidelines are providing recommendations.

European Association of Urology (EAU) guidelines on PCa screening recommend early PSA screening in all men aged $>45$ years with a $\mathrm{FH}$ of $\mathrm{PCa}$, men of African descent aged $>45$ years, and BRCA2 mutation carriers aged $>40$ 
years [17]. The EAU defines FH as three or more affected relatives or two or more relatives with early-onset PCa diagnosed at $<55$ years of age [17]. Genetic sequencing of the primary tumor, liquid biopsies, or human metastatic derivedtissue should be considered early or as soon as the disease is castration resistant. As yet, the guidelines do not recommend the use of any specific panel for the management of $\mathrm{PCa}$ [17].

The European Society for Medical Oncology (ESMO) guidelines resemble those of the EAU in terms of early PSA screening but give a more precise recommendation on genetic testing in metastatic PCa [62].

In contrast, National Comprehensive Cancer Network (NCCN) guidelines have already expanded their recommendation for genetic testing to all patients with a $\mathrm{FH}$ of $\mathrm{PCa}$, high-risk and very high-risk tumors, metastatic setting regardless of $\mathrm{FH}$, Ashkenazi Jewish ancestry, and patients with an intraductal cancer [63]. Given the increased risk for the development of PCa in germline mutation carriers and potentially differing treatment strategies targeting these diseases, the NCCN guidelines recommend germline testing in men with advanced PCa [63]. Table 2 summarizes the current guideline recommendations from the EAU, ESMO, NCCN, and American Urological Association (AUA) [17, 20, 62-67].

Given the recent data supporting genetic workups, the statements from the 2017 and 2019 Philadelphia Prostate Cancer Consensus Conferences on genetic testing are also relevant $[68,69]$. BRCA1/2, $M M R$, and $A T M$ were defined as priority genes. $B R C A 2$ was also recommended for active surveillance management, with early-onset screening (40 years) in BRCA2 mutation carriers, and other genes such as $H O X B 13, A T M, B R C A 1$, and $M M R$ have also been selected for further evaluation. Genetic testing in all patients with metastatic PCa was also strongly recommended $[68,69]$.

\section{Discussion}

As demonstrated by the variety of studies focusing on different genetic mutations associated with $\mathrm{PCa}$, this is a fast-growing field of interest. Although the genetic aspects of PCa may have previously been underestimated, we now have evidence for the impact of genetics in the development of PCa. This is also emphasized by current recommendations for genetic testing in various society guidelines. Although the EAU only gives vague recommendations for early PSA screening in BRCA2 mutation carriers, the NCCN guidelines include patients with high/very high-risk localized disease, those with metastatic disease, patients with Ashkenazi Jewish ancestry, and those with intraductal histology $[17,63,65]$. The ESMO guidelines recommend germline testing in men with advanced $\mathrm{PCa}$ (BRCA2, DDR), regardless of $\mathrm{FH}$ and tumor profile, as well as in patients with localized disease and $\mathrm{FH}$ of hereditary cancers such as BCa [62]. Similarly, the AUA recommends genetic testing in all patients with metastatic disease and those with localized disease with a concomitant positive $\mathrm{FH}$ for hereditary cancers [66].

The trials reviewed in this manuscript indicate a clear increased risk of $\mathrm{PCa}$ among patients with a $\mathrm{FH}$ of $\mathrm{PCa}$ and other HCS such as BCa, OCa, LS, or CRC. Furthermore, a correlation with specific gene mutations was increased for BRCA1/2 and MMR genes, CHEK2, PALB2, HOXB13, and various SNPs.

One limitation of our work is the number of studies with small cohorts and different protocols, which precluded an objective and direct comparison of the studies. Therefore, our descriptive results must be evaluated with caution. Although no clear recommendation is provided for a specific PCa multigene panel, we consider that MGPT platforms, such as ProstateNext, provide the most reliable value for future personalized PCa screening.

Significant evidence indicates that screening programs based on PSA only are not optimal for identifying patients with clinically significant PCa, and result in overtreatment and overdiagnosis. Despite the development of new techniques and the worldwide availability of genetic testing, they remain prohibited in certain countries and centers because of the high associated costs. Therefore, risk calculation systems that encompass a detailed evaluation of $\mathrm{FH}$ in combination with basic diagnostic parameters such as PSA, PSA density, and multiparametric magnetic resonance imaging findings would be ideal. Genetic testing might be included for a more targeted approach in patients who display high-risk features. Additional information provided by MGPT with specific stratification of various risk profiles might be possible and would allow an adapted screening strategy.

Early diagnosis would lead to a higher percentage of patients with curable disease and diminish the risk of overtreatment, therapy-related side effects, and the need for systemic treatments, thereby decreasing overall healthcare costs. Generally, the implementation of genetic testing creates new tasks in the clinical management of patients with PCa. On one hand, genetic testing involves difficult ethical questions with consequences for both the patient and his family. On the other hand, the healthcare system faces increasing costs when integrating broad testing in routine clinical practice. As this is an important topic, and each country handles it differently, satisfactory coverage is beyond the scope of this review. As such, we refer readers to a recent review by Giri et al. [68]. 
Table 2 Current guideline recommendations on genetic testing in prostate cancer (PCa)

\begin{tabular}{|c|c|c|c|}
\hline $\begin{array}{l}\text { European Association of } \\
\text { Urology [16] }\end{array}$ & $\begin{array}{l}\text { National Comprehensive Can- } \\
\text { cer Network }[60,62]\end{array}$ & $\begin{array}{l}\text { European Society for Medical } \\
\text { Oncology [59] }\end{array}$ & $\begin{array}{l}\text { American Urological Association } \\
{[61,63]}\end{array}$ \\
\hline $\begin{array}{l}\text { Early PSA screening in } \\
\text { patients with a FH of PCa } \\
\text { and age }>45 \text { years }\end{array}$ & $\begin{array}{l}\text { Germline testing in all men } \\
\text { with high-risk/very high-risk } \\
\text { regional or metastatic PCa }\end{array}$ & $\begin{array}{l}\text { Early PSA screening in } \\
\text { patients with a } \mathrm{FH} \text { of } \mathrm{PCa} \\
>45 \text { years }\end{array}$ & $\begin{array}{l}\text { Patients with a first-degree relative } \\
\text { diagnosed }<55 \text { years }\end{array}$ \\
\hline $\begin{array}{l}\text { Early PSA screening in } \\
B R C A 2 \text { carriers older }>40 \\
\text { years }\end{array}$ & $\begin{array}{l}\text { Any patient with a FH of } \\
\text { germline mutations/cancers } \\
\text { should be considered for } \\
\text { germline testing }\end{array}$ & $\begin{array}{l}\text { Early PSA screening in } \\
B R C A 1 / 2 \text { carriers }>40 \text { years }\end{array}$ & $\begin{array}{l}\text { Personal diagnosis }<55 \text { years and a } \\
\text { first-degree relative with PCa at any age, or } \\
\text { death of a first-degree relative }<60 \text { years }\end{array}$ \\
\hline \multirow[t]{4}{*}{$\begin{array}{l}\text { Early genetic sequencing of } \\
\text { the primary tumor/biopsy } \\
\text { or metastasis at the state of } \\
\text { metastasis and as soon as } \\
\text { mCRPC }\end{array}$} & $\begin{array}{l}\text { Consider somatic testing in } \\
\text { MSI-H, dMMR or HRR } \\
\text { genes for treatment selection } \\
\text { in metastatic PCa }\end{array}$ & $\begin{array}{l}\text { Germline testing for } B R C A 2 \\
\text { and other DDR genes } \\
\text { associated with cancer } \\
\text { predisposition syndromes } \\
\text { in men with advanced PCa } \\
\text { regardless of tumor features } \\
\text { or FH }\end{array}$ & $\begin{array}{l}\text { Patients with two close blood relatives on the } \\
\text { same family side with at least one diagnosed } \\
<55 \text { years }\end{array}$ \\
\hline & Ashkenazi Jewish ancestry & $\begin{array}{l}\text { Consider somatic tumor } \\
\text { testing for HRR and dMMR } \\
\text { genes in patients with } \\
\text { mCRPC }\end{array}$ & $\begin{array}{l}\text { Patients with any first-degree relative with } \\
\text { hereditary PCa and a diagnosis }<50 \text { years, } \\
\text { or tumor sequencing showing mutations in } \\
\text { hereditary PCa genes }\end{array}$ \\
\hline & \multirow[t]{2}{*}{ Intraductal histology } & $\begin{array}{l}\text { Consider germline screening } \\
\text { for men with localized PCa } \\
\text { with a FH of hereditary } \\
\text { cancer (e.g., BCa, OCa or } \\
\text { PCa) }\end{array}$ & $\begin{array}{l}\text { Patients with high-risk localized } \mathrm{PCa} \text { and a } \\
\text { strong } \mathrm{FH} \text { of specific cancers (BCa, OCa, } \\
\text { pancreatic, gastrointestinal, lymphoma) }\end{array}$ \\
\hline & & $\begin{array}{l}\text { Patients with pathogenic } \\
\text { mutations in cancer-risk } \\
\text { genes identified through } \\
\text { tumor testing should be } \\
\text { referred for germline testing } \\
\text { and genetic counseling }\end{array}$ & $\begin{array}{l}\text { Offer germline testing to patients with } \\
\text { mHSPC and in patients with mCRPC } \\
\text { regardless of age and FH }\end{array}$ \\
\hline
\end{tabular}

$B C a$ breast cancer, $D D R$ DNA-damage response, $d M M R$ deficient mismatch repair, $F H$ family history, $H R R$ homologous recombinant repair, $m C R P C$ metastatic castration-resistant PCa, $m H S P C$ metastatic hormone-sensitive PCa, $M S I-H$ microsatellite instability-high, $O C a$ ovarian cancer, $P C a$ prostate cancer, $P S A$ prostate-specific antigen

\section{Conclusion}

Recent studies have demonstrated a broader genetic landscape in patients with PCa. Mutations in BRCA1/2, MMR, CHEK2, PALB2, and $H O X B 13$ genes, as well as various SNPs, are associated with an increased risk of developing $\mathrm{PCa}$. The implementation of genetic testing in clinical practice, especially in young patients with aggressive tumors or those with positive $\mathrm{FH}$, represents a new challenge for coming years. Genetic testing enables better risk stratification of patients with PCa who may receive targeted therapies, such as PARP inhibitors for BRCA1/2 mutations, facilitating a more personalized approach.

Supplementary Information The online version contains supplementary material available at https://doi.org/10.1007/s40291-021-00529-3.

\section{Declarations}

Funding Open access funding provided byUniversity of Innsbruck and Medical University of Innsbruck. No sources of funding were used to conduct this study or prepare this manuscript.

Conflict of interest Mona Kafka, Cristian Surcel, and Isabel Heidegger have no conflicts of interest that are directly relevant to the content of this article.

Availability of data and material Not applicable.

Ethics approval Not applicable.

Consent Not applicable.

Author contributions $\mathrm{MK}, \mathrm{CS}$, and $\mathrm{IH}$ wrote the manuscript.

Open Access This article is licensed under a Creative Commons Attribution-NonCommercial 4.0 International License, which permits any non-commercial use, sharing, adaptation, distribution and reproduction in any medium or format, as long as you give appropriate credit to the original author(s) and the source, provide a link to the Creative 
Commons licence, and indicate if changes were made. The images or other third party material in this article are included in the article's Creative Commons licence, unless indicated otherwise in a credit line to the material. If material is not included in the article's Creative Commons licence and your intended use is not permitted by statutory regulation or exceeds the permitted use, you will need to obtain permission directly from the copyright holder. To view a copy of this licence, visit http://creativecommons.org/licenses/by-nc/4.0/.

\section{References}

1. Zhou CK, Check DP, Lortet-Tieulent J, Laversanne M, Jemal A, Ferlay J, et al. Prostate cancer incidence in 43 populations worldwide: an analysis of time trends overall and by age group. Int $\mathbf{J}$ Cancer. 2016;138(6):1388-400.

2. Catalona WJ. Prostate cancer screening. Med Clin. 2018;102(2):199-214.

3. Hemminki K, Czene K. Age specific and attributable risks of familial prostate carcinoma from the family-cancer database. Cancer. 2002;95(6):1346-53.

4. Goldgar DE, Easton DF, Cannon-Albright LA, Skolnick MH. Systematic population-based assessment of cancer risk in firstdegree relatives of cancer probands. JNCI J Natl Cancer Inst. 1994;86(21):1600-8.

5. Verhage BAJ, Aben KKH, Witjes JA, Straatman H, Schalken JA, Kiemeney LALM. Site-specific familial aggregation of prostate cancer. Int J Cancer. 2004;109(4):611-7.

6. Grönberg H, Damber L, Damber JE. Familial prostate cancer in Sweden: a nationwide register cohort study. Cancer. 1996;77(1):138-43.

7. Nicolosi P, Ledet E, Yang S, Michalski S, Freschi B, O'Leary $\mathrm{E}$, et al. Prevalence of germline variants in prostate cancer and implications for current genetic testing guidelines. JAMA Oncol. 2019;5(4):523.

8. Lichtenstein P, Holm NV, Verkasalo PK, Iliadou A, Kaprio J, Koskenvuo M, et al. Environmental and heritable factors in the causation of cancer-analyses of cohorts of twins from Sweden, Denmark, and Finland. N Engl J Med. 2000;343(2):78-85.

9. Hjelmborg JB, Scheike T, Holst K, Skytthe A, Penney KL, Graff RE, et al. The heritability of prostate cancer in the nordic twin study of cancer. Cancer Epidemiol Prev Biomark. 2014;23(11):2303-10.

10. Carter Bob S, Steven BG, Beaty Terri H, Steinberg Gary D, Childs B, Isaacs William B, et al. Hereditary prostate cancer: epidemiologic and clinical features. J Urol. 1993;150(3):797-802.

11. Zeegers MPA, Jellema A, Ostrer H. Empiric risk of prostate carcinoma for relatives of patients with prostate carcinoma. Cancer. 2003;97(8):1894-903.

12. Albright F, Stephenson RA, Agarwal N, Teerlink CC, Lowrance WT, Farnham JM, et al. Prostate cancer risk prediction based on complete prostate cancer family history. Prostate. 2015;75(4):390-8.

13. Lee MV, Katabathina VS, Bowerson ML, Mityul MI, Shetty AS, Elsayes KM, et al. BRCA-associated cancers: role of imaging in screening, diagnosis, and management. Radiographics. 2017;37(4):1005-23.

14. Cerhan JR, Parker AS, Putnam SD, Chiu BC-H, Lynch CF, Cohen $\mathrm{MB}$, et al. Family history and prostate cancer risk in a population-based cohort of Iowa men. Cancer Epidemiol Prev Biomark. 1999;8(1):53-60.

15. Kalish LA, McDougal WS, McKinlay JB. Family history and the risk of prostate cancer. Urology. 2000;56(5):803-6.
16. Hemminki K. Familial risk and familial survival in prostate cancer. World J Urol. 2012;30(2):143-8.

17. Cornford P, van den Bergh RCN, Briers E, Van den Broeck T, Cumberbatch MG, De Santis M, et al. EAU-EANM-ESTROESUR-SIOG guidelines on prostate cancer. Part II-2020 update: treatment of relapsing and metastatic prostate cancer. Eur Urol [Internet]. 2020. http://www.sciencedirect.com/science/article/ pii/S0302283820307739. https://doi.org/10.1016/j.eururo.2020. 09.046

18. Ni Raghallaigh H, Eeles R. Genetic predisposition to prostate cancer: an update. Fam Cancer [Internet]. 2021.https://doi.org/ 10.1007/s10689-021-00227-3

19. Hart SN, Ellingson MS, Schahl K, Vedell PT, Carlson RE, Sinnwell JP, et al. Determining the frequency of pathogenic germline variants from exome sequencing in patients with castrate-resistant prostate cancer. BMJ Open. 2016;6(4):e010332.

20. Loeb S, Giri VN. Clinical implications of germline testing in newly diagnosed prostate cancer. Eur Urol Oncol. 2021;4(1):1-9.

21. Szymaniak BM, Facchini LA, Giri VN, Antonarakis ES, Beer TM, Carlo MI, et al. Practical considerations and challenges for germline genetic testing in patients with prostate cancer: recommendations from the germline genetics working group of the PCCTC. JCO Oncol Pract. 2020;16(12):811-9.

22. Kratz CP, Achatz MI, Brugières L, Frebourg T, Garber JE, Greer M-LC, et al. Cancer screening recommendations for individuals with Li-Fraumeni syndrome. Clin Cancer Res. 2017;23(11):e38-45.

23. Pilarski R, Burt R, Kohlman W, Pho L, Shannon KM, Swisher E. Cowden syndrome and the PTEN hamartoma tumor syndrome: systematic review and revised diagnostic criteria. JNCI J Natl Cancer Inst. 2013;105(21):1607-16.

24. Barrow PJ, Ingham S, O'Hara C, Green K, McIntyre I, Lalloo F, et al. The spectrum of urological malignancy in Lynch syndrome. Fam Cancer. 2013;12(1):57-63.

25. Pakkanen S, Matikainen MP, Ha N, Kujala P, Koivisto PA, Schleutker J, et al. N8 Clinical and histopathological characteristics of Finnish familial prostate cancers. Eur Urol Suppl. 2009;8(8):570.

26. Beebe-Dimmer JL, Kapron AL, Fraser AM, Smith KR, Cooney KA. Risk of prostate cancer associated with familial and hereditary cancer syndromes. J Clin Oncol. 2020;38(16):1807-13.

27. Chandrasekar T, Gross L, Gomella LG, Hegarty SE, Leong JY, Giri VN. Prevalence of suspected hereditary cancer syndromes and germline mutations among a diverse cohort of probands reporting a family history of prostate cancer: toward informing cascade testing for men. Eur Urol Oncol. 2020;3(3):291-7.

28. Ryan S, Jenkins MA, Win AK. Risk of prostate cancer in lynch syndrome: a systematic review and meta-analysis. Cancer Epidemiol Prev Biomark. 2014;23(3):437-49.

29. Kerr L, Rewhorn MJ, Longmuir M, Fraser S, Walsh S, Andrew $\mathrm{N}$, et al. A cohort analysis of men with a family history of BRCA1/2 and Lynch mutations for prostate cancer. BMC Cancer. 2016;16(1):529.

30. Haraldsdottir S, Hampel H, Wei L, Wu C, Frankel W, Bekaii-Saab $\mathrm{T}$, et al. Prostate cancer incidence in males with Lynch syndrome. Genet Med Off J Am Coll Med Genet. 2014;16(7):553-7.

31. Bancroft EK, Page EC, Castro E, Lilja H, Vickers A, Sjoberg D, et al. Targeted prostate cancer screening in BRCA1 and BRCA2 mutation carriers: results from the initial screening round of the IMPACT study. Eur Urol. 2014;66(3):489.

32. Page EC, Bancroft EK, Brook MN, Assel M, Hassan Al Battat M, Thomas $\mathrm{S}$, et al. Interim results from the IMPACT study: evidence for prostate-specific antigen screening in BRCA2 mutation carriers. Eur Urol. 2019;76(6):831-42.

33. Maia S, Cardoso M, Paulo P, Pinheiro M, Pinto P, Santos C, et al. The role of germline mutations in the BRCA1/2 and mismatch 
repair genes in men ascertained for early-onset and/or familial prostate cancer. Fam Cancer. 2016;15(1):111-21.

34. Patel VL, Busch EL, Friebel TM, Cronin A, Leslie G, McGuffog $\mathrm{L}$, et al. Association of genomic domains in BRCA1 and BRCA2 with prostate cancer risk and aggressiveness. Cancer Res. 2020;80(3):624-38.

35. Mersch J, Jackson MA, Park M, Nebgen D, Peterson SK, Singletary C, et al. Cancers associated with BRCA1 and BRCA2 mutations other than breast and ovarian. Cancer. 2015;121(2):269-75.

36. Silvestri V, Leslie G, Barnes DR, Group and the C, Agnarsson BA, Aittomäki K, et al. Characterization of the cancer spectrum in men with germline BRCA1 and BRCA2 pathogenic variants: results from the consortium of investigators of modifiers of BRCA1/2 (CIMBA). JAMA Oncol. 2020;6(8):1218-30.

37. Sutcliffe EG, Stettner AR, Miller SA, Solomon SR, Marshall ML, Roberts ME, et al. Differences in cancer prevalence among CHEK2 carriers identified via multi-gene panel testing. Cancer Genet. 2020;1(246):12-7.

38. Southey MC, Goldgar DE, Winqvist R, Pylkäs K, Couch F, Tischkowitz M, et al. PALB2, CHEK2 and ATM rare variants and cancer risk: data from COGS. J Med Genet. 2016;53(12):800-11.

39. Cybulski C, Wokołorczyk D, Kluźniak W, Kashyap A, Gołąb A, Słojewski M, et al. A personalised approach to prostate cancer screening based on genotyping of risk founder alleles. Br J Cancer. 2013;108(12):2601-9.

40. Ewing CM, Ray AM, Lange EM, Zuhlke KA, Robbins CM, Tembe WD, et al. Germline mutations in HOXB13 and prostatecancer risk [Internet]. 2012. https://doi.org/10.1056/NEJMoa1110 000. Cited 2020 Sept 14.

41. Heise M, Jarzemski P, Bak A, Junkiert-Czarnecka A, PilarskaDeltow M, Haus O. G84E germline mutation in HOXB13 gene is associated with increased prostate cancer risk in Polish men. Pol J Pathol Off J Pol Soc Pathol. 2019;70(2):127-33.

42. MacInnis RJ, Severi G, Baglietto L, Dowty JG, Jenkins MA, Southey MC, et al. Population-based estimate of prostate cancer risk for carriers of the HOXB13 missense mutation G84E. PLoS ONE [Internet]. 2013 [cited 2020 Sep 16];8(2).

43. Kote-Jarai Z, Mikropoulos C, Leongamornlert DA, Dadaev T, Tymrakiewicz M, Saunders EJ, et al. Prevalence of theHOXB13 G84E germline mutation in British men and correlation with prostate cancer risk, tumour characteristics and clinical outcomes. Ann Oncol. 2015;26(4):756-61.

44. Seibert TM, Fan CC, Wang Y, Zuber V, Karunamuni R, Parsons $\mathrm{JK}$, et al. Polygenic hazard score to guide screening for aggressive prostate cancer: development and validation in large scale cohorts. BMJ [Internet]. 2018;360. https://www.bmj.com/content/360/bmj. j5757. Cited 15 Sept 2020.

45. Huynh-Le M-P, Fan CC, Karunamuni R, Walsh EI, Turner EL, Lane JA, et al. A genetic risk score to personalize prostate cancer screening, applied to population data. Cancer Epidemiol Prev Biomark. 2020;29(9):1731-8.

46. Cremers RG, Galesloot TE, Aben KK, van Oort IM, Vasen HF, Vermeulen $\mathrm{SH}$, et al. Known susceptibility SNPs for sporadic prostate cancer show a similar association with "hereditary" prostate cancer. Prostate. 2015;75(5):474-83.

47. Wallander K, Liu W, von Holst S, Thutkawkorapin J, Kontham V, Forsberg A, et al. Genetic analyses supporting colorectal, gastric, and prostate cancer syndromes. Genes Chromosomes Cancer. 2019;58(11):775-82.

48. Pritzlaff M, Tian Y, Reineke P, Stuenkel AJ, Allen K, Gutierrez $\mathrm{S}$, et al. Diagnosing hereditary cancer predisposition in men with prostate cancer. Genet Med. 2020;22(9):1517-23.

49. Pilié PG, Johnson AM, Hanson K, Dayno ME, Kapron AL, Stoffel EM, et al. Germline genetic variants in men with prostate cancer and one or more additional cancers. Cancer. 2017;123(20):3925-32.
50. Rosenthal ET, Bernhisel R, Brown K, Kidd J, Manley S. Clinical testing with a panel of 25 genes associated with increased cancer risk results in a significant increase in clinically significant findings across a broad range of cancer histories. Cancer Genet. 2017;1(218-219):58-68.

51. Momozawa Y, Iwasaki Y, Hirata M, Liu X, Kamatani Y, Takahashi A, et al. Germline pathogenic variants in 7636 Japanese patients with prostate cancer and 12366 controls. JNCI J Natl Cancer Inst. 2019;112(4):369-76.

52. Kwon DH-M, Borno HT, Cheng HH, Zhou AY, Small EJ. Ethnic disparities among men with prostate cancer undergoing germline testing. Urol Oncol Semin Orig Investig. 2020;38(3):80.e1-7.

53. Cheng H, Powers J, Schaffer K, Sartor O. Practical methods for integrating genetic testing into clinical practice for advanced prostate cancer. Am Soc Clin Oncol Educ Book. 2018;38:372-81.

54. Slavin TP, Banks KC, Chudova D, Oxnard GR, Odegaard JI, Nagy $\mathrm{RJ}$, et al. Identification of incidental germline mutations in patients with advanced solid tumors who underwent cell-free circulating tumor DNA sequencing. J Clin Oncol. 2018;36(35):3459-65.

55. Yang X, Leslie G, Doroszuk A, Schneider S, Allen J, Decker B, et al. Cancer risks associated with germline PALB2 pathogenic variants: an international study of 524 families. J Clin Oncol. 2019;38(7):674-85.

56. Mantere T, Haanpää M, Hanenberg H, Schleutker J, Kallioniemi A, Kähkönen M, et al. Finnish Fanconi anemia mutations and hereditary predisposition to breast and prostate cancer. Clin Genet. 2015;88(1):68-73.

57. Marchesani M, Hakkarainen A, Tuomainen T-P, Kaikkonen J, Pukkala E, Uimari $P$, et al. New paraoxonase 1 polymorphism I102V and the risk of prostate cancer in Finnish Men. JNCI J Natl Cancer Inst. 2003;95(11):812-8.

58. Heise M, Jarzemski P, Bak A, Junkiert-Czarnecka A, Pilarska-Deltow M, Borysiak M, et al. Clinical significance of PON1 L55M, Q192R and I102V polymorphisms and their association with prostate cancer risk in Polish men. Pol J Pathol. 2020;71(1):55-61.

59. Ābele A, Vjaters E, Irmejs A, Trofimovičs G, Miklaševičs E, Gardovskis J. Epidemiologic, clinical, and molecular characteristics of hereditary prostate cancer in Latvia. Medicina (Mex). 2011;47(10):83.

60. Deng W, Li J, Dorrah K, Jimenez-Tapia D, Arriaga B, Hao Q, et al. The role of PPM1D in cancer and advances in studies of its inhibitors. Biomed Pharmacother. 2020;1(125):109956.

61. Cardoso M, Paulo P, Maia S, Teixeira MR. Truncating and missense PPM1D mutations in early-onset and/or familial/hereditary prostate cancer patients. Genes Chromosomes Cancer. 2016;55(12):954-61.

62. Parker C, Gillessen S, Heidenreich A, Horwich A. Cancer of the prostate: ESMO clinical practice guidelines for diagnosis, treatment and follow-up. Ann Oncol. 2015;26(suppl_5):v69-77.

63. Carroll PH, Mohler JL. NCCN guidelines updates: prostate cancer and prostate cancer early detection. J Natl Compr Cancer Netw. 2018;16(5S):620-3.

64. Heidegger I, Tsaur I, Borgmann H, Surcel C, Kretschmer A, Mathieu R, et al. Hereditary prostate cancer-primetime for genetic testing? Cancer Treat Rev. 2019;1(81):101927.

65. Mohler JL, Antonarakis ES, Armstrong AJ, D’Amico AV, Davis BJ, Dorff T, et al. Prostate cancer, Version 2.2019, NCCN clinical practice guidelines in oncology. J Natl Compr Canc Netw. 2019;17(5):479-505.

66. Sanda Martin G, Cadeddu Jeffrey A, Kirkby E, Chen Ronald C, Crispino T, Fontanarosa J, et al. Clinically localized prostate cancer: AUA/ASTRO/SUO guideline. Part I: risk stratification, shared decision making, and care options. J Urol. 2018;199(3):683-90.

67. Merseburger AS, Waldron N, Ribal MJ, Heidenreich A, Perner $\mathrm{S}$, Fizazi K, et al. Genomic testing in patients with metastatic 
castration-resistant prostate cancer: a pragmatic guide for clinicians. Eur Urol. 2021;79(4):519-29.

68. Giri VN, Knudsen KE, Kelly WK, Cheng HH, Cooney KA, Cookson MS, et al. Implementation of germline testing for prostate cancer: philadelphia prostate cancer consensus conference 2019. J Clin Oncol. 2020;38(24):2798-811.
69. Giri VN, Knudsen KE, Kelly WK, Abida W, Andriole GL, Bangma $\mathrm{CH}$, et al. Role of genetic testing for inherited prostate cancer risk: Philadelphia prostate cancer consensus conference 2017. J Clin Oncol. 2018;36(4):414-24. 